\title{
Revisitando alguns Conceitos da Teoria do Apego: Comportamento versus Representação? ${ }^{1}$
}

\author{
Vera Regina Röhnelt Ramires ${ }^{2}$ \\ Michele Scheffel Schneider \\ Universidade do Vale do Rio dos Sinos (UNISINOS)
}

\begin{abstract}
RESUMO - Este artigo propõe uma releitura de alguns conceitos da teoria do apego, especialmente os de apego, comportamento de apego e modelo representacional interno. Visa discutir tais conceitos à luz das concepções de Bowlby e de autores contemporâneos. A dicotomia entre comportamento e representação do apego é questionada, bem como a estabilidade e unicidade do modelo representacional interno, com base na análise das contribuições dos principais teóricos desse campo, especialmente na vertente psicanalítica. Discute-se a importância da dimensão representacional e seu papel regulador das emoções e organizador do self, as implicações desses papéis para a Psicologia Clínica e do Desenvolvimento e para futuros estudos.
\end{abstract}

Palavras-chave: apego e psicanálise; comportamento de apego; representação do apego.

\section{Revisiting some Attachment Theory Concepts: Behavior versus Representation?}

\begin{abstract}
This paper proposes a revision of some attachment theory concepts, especially those about attachment, attachment behavior, and internal representational model. It discusses such concepts according to the ideas of Bowlby and some contemporary authors. The dichotomy between behavior and attachment representation is questioned, as well as the stability and specificity of the internal representational model, based on the main theoreticians of this field, especially the psychoanalytical ones. It is evaluated the relevance of the representational dimension and its role as emotions' regulator and self organizer, and the implications of such roles for Clinical and Development Psychology and for future studies.
\end{abstract}

Keywords: attachment and psychoanalysis; attachment behavior; attachment representation.

O objetivo deste artigo é discutir alguns conceitos da teoria do apego, partindo das concepções de Bowlby e retomando-os à luz das concepções de autores contemporâneos, especialmente na vertente psicanalítica da teoria. Há uma vasta literatura dedicada ao tema do apego, podendo-se identificar contribuições ancoradas numa perspectiva mais cognitiva, e outras numa perspectiva mais psicanalítica. Encontra-se uma diversidade de termos como "modelo funcional do eu", "modelo funcional interno", "modelo de trabalho interno", "modelo operante interno", "modelo representacional interno", "representações mentais", "scripts", "estilo de apego", "padrão de apego", "comportamento de apego", "sistemas comportamentais" e, mais recentemente, "estados mentais", "apego compartilhado" e "modelo funcional compartilhado", muitas vezes sem uma definição clara. Sem pretender esgotar essa discussão, busca-se focalizar, especialmente, o conceito de modelo funcional ou modelo representacional interno e sua relação com o conceito de comportamento de apego, tendo em vista o interesse no tema da especificidade, e da estabilidade ou mudança do padrão de apego de uma pessoa.

Inicia-se revisando algumas contribuições de Bowlby a respeito dos conceitos de apego, comportamento de apego,

1 Este artigo deriva da Dissertação de Mestrado da segunda autora, realizada no Programa de Pós-Graduação em Psicologia da UNISINOS, sob orientação da primeira autora.

2 Endereço para correspondência: Av. Carlos Gomes 911, ap. 201. Porto Alegre, RS. CEP 90480-004. Fone: (51) 3331-6919. Fax: (51) 35908122.E-mail:veraramires@terra.com.br,vramires@unisinos.br. sistemas comportamentais e modelo funcional ou modelo representacional interno. Aborda-se, a seguir, o crescente reconhecimento da importância da dimensão representacional do apego, do conceito de modelo funcional ou modelo representacional interno, sua complexidade e a inter-relação entre conceitos da teoria do apego e de outras vertentes da teoria psicanalítica. Finalmente, algumas considerações a respeito das implicações da teoria para a Psicologia Clínica e para a Psicologia do Desenvolvimento são feitas.

\section{Bowlby e a Teoria do Apego}

Como Bowlby (1979/1997) assinala, até meados da década de 50 do século passado predominava uma concepção de que a formação e manutenção dos vínculos sustentavam-se na necessidade de satisfazer certos impulsos, como a alimentação na infância e o sexo na vida adulta. Em contrapartida, esse autor postulou que existe nos bebês uma propensão inata para o contato com um ser humano, o que implica na "necessidade" de um objeto independente do alimento, tão primária quanto a "necessidade" de alimento e conforto, alicerçando sua teoria no relato de farta pesquisa empírica (Bowlby, 1969/1990).

Para Bowlby (1988/1989), a teoria do apego foi desenvolvida como uma variante da teoria das relações objetais. Como seu ponto de partida foi a observação do comportamento, foi tomada por alguns clínicos como uma versão do behaviorismo, equívoco que decorre, para o autor, da confusão entre apego e comportamento de apego. 
Apego é um tipo de vínculo no qual o senso de segurança de alguém está estreitamente ligado à figura de apego. No relacionamento com a figura de apego, a segurança e o conforto experimentados na sua presença permitem que seja usado como uma "base segura", a partir da qual poderá se explorar o resto do mundo (Bowlby, 1979/1997).

Em 1969/1990, Bowlby assinalou que apego-cuidado é um tipo de vínculo social baseado no relacionamento complementar entre pais e filhos. $\mathrm{O}$ apego tem sua própria motivação interna, distinta da alimentação e do sexo, como postulado pela teoria freudiana, e de igual importância para a sobrevivência (Bowlby, 1988/1989). Sendo o apego um estado interno, sua existência pode ser observada através dos comportamentos de apego. Tais comportamentos possibilitam ao indivíduo conseguir e manter a proximidade em relação a uma figura de apego, ou seja, um indivíduo claramente identificado, considerado mais apto para lidar com o mundo. Sorrir, fazer contato visual, chamar, tocar, agarrar-se, chorar, ir atrás são alguns desses comportamentos.

Uma diferença importante entre "apego" e "comportamento de apego" é que se o "comportamento de apego pode, em circunstâncias diferentes, ser mostrado a uma variedade de indivíduos, um apego duradouro ou laço de apego é restrito a muito poucos" (Bowlby, 1988/1989, p. 40). A teoria do apego ocupa-se de ambos. Um conceito-chave dessa teoria, para o autor, é o de sistema comportamental.

O sistema comportamental seria um sistema básico de comportamento, enraizado biologicamente e característico da espécie. O sistema subjacente ao comportamento de apego é tão fundamental como parte do equipamento de muitas espécies quanto os sistemas subjacentes ao comportamento reprodutivo, o comportamento parental, o comportamento de alimentação, o comportamento exploratório, e ele não deriva de nenhum destes. Como outros sistemas básicos, o de apego é supostamente pertencente a um processo de seleção natural, pois oferece uma vantagem em termos de sobrevivência, pelas chances de proteção obtidas pela proximidade das figuras de apego. Os sistemas comportamentais incluem não somente manifestações externas, mas também uma organização interna, a qual presume-se que tenha raízes nos processos neurofisiológicos. Essa organização interna é objeto de mudança desenvolvimental, não apenas sob orientação genética, mas também pelas influências do ambiente (Ainsworth, 1989; Bowlby, 1969/1990).

Os sistemas comportamentais transcendem o que é chamado de comportamento "instintivo", seja qual for a acepção do termo. Bowlby (1969/1990) levanta esse argumento ao destacar o papel da linguagem, característica singular que traz como benefício a possibilidade, para o ser humano, ao construir seus modelos representacionais, de apoiar-se nos modelos construídos pelos outros. Os sistemas comportamentais são organizados hierarquicamente por meio da linguagem, apoiando-se em modelos representacionais refinados do organismo e do ambiente.

Bowlby (1988/1989) postula, portanto, “a existência de uma organização psicológica interna, com um certo número de traços altamente específicos, que incluem modelos representativos do self e da(s) figura(s) de apego" (p. 41). Ao final do primeiro ano de vida, e durante os segundo e terceiro anos, quando adquire a linguagem, a criança se habilita a construir modelos funcionais de como esperar que o mundo físico se comporte, como a mãe e outras pessoas significativas poderão se comportar, acerca dela mesma e das interações entre todos. Tais modelos influem na percepção e na avaliação e podem ser mais ou menos válidos ou distorcidos (Bowlby, 1969/1990).

O modelo funcional do self é um elemento-chave para a noção de quão aceitável ou inaceitável a criança é, aos olhos das suas figuras de apego (Bowlby, 1973/1998a). Além disso, a interpretação e avaliação que fazemos de cada situação, a partir de nossos modelos funcionais, determina aquilo que sentimos (Bowlby, 1973/1998b). Ainda, como os dados para a construção dos modelos vêm de múltiplas fontes, há a possibilidade de existirem dados incompatíveis, podendo essa incompatibilidade, para algumas crianças, ser regular e persistente.

Em publicação de 1988/1989, Bowlby assinala que anteriormente utilizou o termo "modelo representacional" como sinônimo de "modelo funcional", devido à familiaridade do conceito de representação na literatura clínica. Entretanto, considerou que numa psicologia dinâmica, o termo modelo funcional seria mais apropriado, além de também ser mais utilizado pelos psicólogos cognitivos.

Bowlby (1988/1989) equipara o conceito de modelo funcional na teoria do apego ao de objeto interno na teoria psicanalítica das relações objetais. Ao mesmo tempo, relaciona esse conceito aos processos e capacidades cognitivas, ponto que havia aprofundado anteriormente em seu escrito sobre perdas (1973/1998b). Assim, os modelos funcionais se estabelecem como estruturas cognitivas influentes e são baseados em experiências de vida da criança, nas suas interações com seus cuidadores. Uma vez construídos, Bowlby (1973/1998b) acreditava que os modelos dos pais e do self em interação tendem a persistir e passam a atuar em nível inconsciente. No decorrer do desenvolvimento (à medida que a criança seguramente apegada cresce e os pais a tratam de forma diferente), ocorre uma atualização gradual dos modelos. Por outro lado, nas crianças ansiosamente apegadas parece haver uma dificuldade e rigidez maior na atualização dos modelos.

\section{A Importância da Dimensão Representacional do Apego}

Main (2000) considera que o estudo do apego desenvolveu-se em três fases principais: a primeira corresponde aos estudos de Bowlby, alicerçado nas observações de primatas não humanos e nos trabalhos com crianças que haviam sido separadas de seus pais e colocadas em ambientes não familiares, como hospitais ou casas abrigo. A segunda fase foi liderada por Ainsworth, com as suas observações naturalistas da interação mãe-bebê nos lares de Kampala (Uganda) e em Baltimore (Maryland). Junto com o estudo de Baltimore, Ainsworth desenvolveu o procedimento de laboratório conhecido como Situação Estranha, que resultou no sistema de classificação da organização do apego do bebê em relação às figuras parentais ou cuidadores substitutos (seguro, inseguro evitativo e inseguro ambivalente ou resistente). Tais achados foram recebidos com grande entusiasmo pela comunidade 
científica, e resultaram numa imensidade de estudos e pesquisas, em outras fases do ciclo vital inclusive.

A terceira fase no estudo do apego foi inaugurada com um movimento para o nível da representação (Main, 2000; Main, Kaplan \& Cassidy, 1985). Em um estudo que pode ser considerado um divisor de águas na pesquisa sobre o apego, essas autoras relatam uma forte correlação entre as representações das mães acerca do seu relacionamento com os objetos primários e o comportamento de apego dos seus bebês, conforme observados no procedimento da Situação Estranha de Ainsworth. Para a realização dessa análise, criaram uma entrevista, a Adult Attachment Interview - AAI (George, Kaplan \& Main, 1985), baseada na narrativa das mães ou dos pais sobre suas experiências de apego em sua infância precoce.

Numa tentativa de compreender as diferenças individuais nos relacionamentos de apego, Main e cols. (1985) propõem uma mudança no foco de análise, para o nível da representação. Contrastando com a abordagem corrente predominante até então, centrada no nível comportamental, essas autoras compreendem as diferenças na organização do apego como diferenças individuais na representação mental do self em relação ao apego, conduzindo a um novo foco na representação e na linguagem. Nessa ótica, a segurança ou insegurança do apego é melhor compreendida em referência a modelos funcionais internos particulares dos relacionamentos, que direcionam, além dos sentimentos e comportamentos, a atenção, a memória e a cognição.

Para Main e cols. (1985), o modelo funcional interno é uma representação mental de aspectos do mundo, dos outros, do self, dos relacionamentos com os outros que são relevantes para o indivíduo. Inclui componentes afetivos e cognitivos. As autoras afirmam que esse modelo é um componente integral do sistema comportamental de apego, que direciona avaliações da experiência e guia o comportamento. Os padrões de resposta segura, insegura evitativa e insegura ambivalente, identificadas na Situação Estranha de Ainsworth, seriam expressões de modelos funcionais particulares dos relacionamentos, que poderiam guiar o comportamento em outros contextos.

O modelo funcional interno do relacionamento com a figura de apego reflete a história das respostas do cuidador às ações do bebê ou tentativas de ações em direção a essa figura. Decorrem, portanto, de representações generalizadas de eventos. Uma vez formados, esses modelos têm uma existência fora da consciência e uma propensão à estabilidade. Sua formação inicia-se durante o primeiro ano de vida e tais modelos provêm regras para a direção do comportamento, avaliação da experiência, organização da atenção e da memória. Tais regras permitem ou limitam o acesso do indivíduo a certas formas de conhecimento a respeito do self, da figura de apego e do relacionamento entre ambos, e serão refletidas na organização do pensamento e da linguagem, na medida em que se relacionam direta e indiretamente ao apego (Main $\&$ cols., 1985).

Os modelos funcionais internos são, portanto, representações ligadas ao apego (Bretherton \& Munholland, 1999). Apego, diferentemente de comportamento de apego, é um tipo de vínculo afetivo (Ainsworth, 1989; Bowlby, 1979/1997). É importante a elucidação desses conceitos, para que se possa discutir sua articulação. Ainsworth (1989) define vínculo afetivo como "um laço relativamente durável em que o parceiro é importante como um indivíduo único e não pode ser trocado por nenhum outro. Num vínculo afetivo, existe o desejo de manter uma proximidade com o parceiro" (p. 711). Já o conceito de apego diz respeito a uma subvariedade do vínculo afetivo, no qual o senso de segurança de alguém está estreitamente ligado ao relacionamento. Os vínculos afetivos e os apegos são estados ou representações internas e sua existência pode ser observada através dos comportamentos de apego.

O conceito de vínculo afetivo proposto por Ainsworth (1989), na medida em que implica uma representação na organização interna, aproxima-se do conceito de modelo funcional ou modelo representacional interno. Ambos se referem a representações de relacionamentos e/ou de interações com figuras significativas.

Bretherton e Munholland (1999) sublinham a importância do conceito de modelos funcionais ou representacionais, lembrando que, embora Bowlby tenha se dedicado primordialmente ao estudo da construção, uso e revisão dos modelos funcionais internos do self e do outro, relacionados ao apego, frequentemente se esquece que para ele esse é um constructo geral e se aplica a todas as representações, para além das relacionadas aos vínculos de apego. Essas autoras destacam que Bowlby esforçou-se para demonstrar o papel dos modelos funcionais internos, em conjunto com o sistema comportamental de apego, na regulação dos relacionamentos de apego (Bowlby, 1969/1990). Sua discussão ressalta o caráter dinâmico e interativo desses modelos, e amplia o papel do indivíduo na construção dos mesmos.

À medida que se engajam em diálogos verbais sobre os modelos funcionais, os pais servem como base segura para a exploração do mundo interno das suas crianças, para além da exploração do mundo externo. Bretherton e Munholland (1999), apoiando-se também nas contribuições de campos teóricos correlatos como teoria cognitiva e psicologia social, mostram que pais suportivos servem como base segura para que suas crianças se engajem em diálogos verbais. À medida que esses pais abertamente compartilham suas reflexões sobre os modelos funcionais com seus filhos, eles os ajudam a construir e a revisar apropriadamente seus próprios modelos funcionais internos.

Dessa forma, conversações relevantes para o apego, e não somente as interações relacionadas ao apego, contribuem para a construção dos modelos funcionais internos (Bretherton \& Munholland, 1999). Mais do que isso, os modelos funcionais têm uma função regulatória, defensiva e também positiva para o fortalecimento do self, por meio da qual os indivíduos criam realidades ou significados individuais e socialmente compartilhados. Isso significa que a função regulatória da representação implica não apenas em refletir a realidade, mas também em criar a realidade.

A reconceitualização do apego como representação, desenvolvida inicialmente por Main e cols. (1985), permitiu um crescente interesse de psicanalistas no campo da pesquisa sobre o apego (Eagle, 1997; Fonagy, 1999, 2000, 2001; Lyons-Ruth \& Jacobovitz, 1999; Slade, 1996, 1999, 2000; Target, 2005/2007). Até então, com o afastamento de Bowlby da Sociedade Britânica de Psicanálise, e sua aproximação da 
Psicologia acadêmica, tal como testemunha a colaboração de Mary Ainsworth, psicanalistas e teóricos e pesquisadores do apego pouco dialogaram.

Target (2005/2007) sintetiza as críticas que eram dirigidas à teoria do apego: a sua excessiva ênfase no valor de sobrevivência evolucionista; a redução da motivação a um sistema básico e a exclusão do inconsciente dinâmico; a concentração na segurança e no perigo, colocando em segundo plano toda a extensão da vida emocional humana; o foco prioritário na separação e outros traumas do apego, deixando de lado outras vulnerabilidades biológicas e sociais; e o fato de ignorar o desenvolvimento do ego e os posteriores processos psicossexuais.

Entretanto, o trabalho de Main e cols. (1985) deslocou o foco do comportamento para o mundo das representações, objeto de interesse dos psicanalistas. Target (2005/2007) assinala que, partindo de uma forte base empírica, a teoria do apego disponibiliza uma perspectiva unificadora que abrange todo o ciclo vital. Essa teoria oferece um modo sistemático de compreender e pesquisar os impactos dos relacionamentos emocionais iniciais e os posteriores, as experiências traumáticas, a intimidade, a ansiedade, as relações e os vínculos afetivos.

O estudo de Main e cols. (1985) permitiu constatar que, mesmo com histórias desfavoráveis em relação às suas figuras de apego da infância, muitos adultos podiam ser considerados seguros autônomos, de acordo com a AAI, uma vez que eram capazes de produzir uma narrativa coerente, clara, organizada e suficientemente aberta emocionalmente. Consequentemente, o que parece ser decisivo para a definição da qualidade da segurança desses adultos em relação ao apego não é o comportamento dos pais ou as vivências com eles na infância, mas sim a organização dos seus modelos representacionais internos. Além disso, as autoras encontraram uma correlação entre os resultados da entrevista desses pais e mães e o comportamento de apego dos seus bebês quando avaliados na Situação Estranha de Ainsworth. Assim, pais e mães considerados como seguros-autônomos na AAI (ainda que com histórias de apego desfavoráveis) tiveram bebês classificados como seguros na Situação Estranha.

Esses achados sugerem que a capacidade do pai ou da mãe de regular seus próprios estados afetivos conflitivos e impulsos derivados permite que eles desempenhem uma função regulatória para a criança na interação. Isso decorre da sua capacidade de imaginar experiências afetivas nas suas crianças mesmo antes do seu nascimento, reconhecê-las e responder a elas por meio do comportamento. A mãe pode, por exemplo, sintetizar e integrar para o bebê experiências que ela é capaz de sintetizar e integrar nela mesma e, ao contrário, fragmentação e distorção nas suas respostas ao afeto conduzem à falhas empáticas e à regulação inconsistente (Bretherton \& Munholland, 1999; Fonagy, Gergely, Jurist \& Target, 2002; Slade, 1996).

Sroufe (citada por Target, 2005/2007) propôs uma releitura da teoria do apego em termos de regulação do afeto. O sistema de apego seria o primeiro e o principal regulador emocional da experiência, visando ao seu objetivo maior - a experiência de segurança. Não se nasce com capacidade para regular as próprias reações emocionais. No contexto de um sistema regulatório diádico, os sinais da criança a respeito das alterações em seu estado são compreendidas e respondidas pelo cuidador, e dessa forma alcançam sua regulação. As experiências passadas do bebê serão agregadas nos sistemas representacionais. Dessa maneira, "o sistema de apego é um sistema regulatório homeostático biossocial aberto" (Fonagy $\&$ cols., 2002, p. 15).

Nessa ótica, pessoas com apego seguro seriam possuidoras de capacidades internalizadas de autoregulação, ao contrário daquelas que suprimem o afeto (evitativas), ou das que o aumentam (resistentes/ambivalentes). Situações de estresse (doença, perda, medo etc.) ou um desenvolvimento insuficiente das capacidades internas de regulação do afeto fazem com que crianças mais velhas e adultos continuem monitorando a acessibilidade e a responsividade das figuras de apego (Target, 2005/2007).

$\mathrm{O}$ conceito de função reflexiva que vem sendo desenvolvido por Fonagy (1999, 2000; Fonagy \& cols., 2002) auxilia bastante na elucidação dessa possibilidade. Pesquisas mencionadas por Fonagy $(1999,2000)$ constataram que cuidadores com capacidade reflexiva promovem com mais probabilidade apego seguro em suas crianças, e que um ciclo de desvantagem e de persistências transgeracionais de vínculos inseguros e fragilizados pode ser interrompido se o cuidador adquirir a capacidade de refletir produtivamente sobre a experiência mental. A capacidade dos cuidadores de observar e compreender os estados mentais das crianças, de nomear suas experiências emocionais, permite à criança a aquisição dessas mesmas capacidades. Esse processo também foi teorizado por Bion (1962/1997) e por Winnicott (1978/2000, 1979/1982), quando esses autores descreveram aquilo que chamaram de capacidade de reverie materna, e de uma mãe suficientemente boa, respectivamente.

A função reflexiva se refere à operacionalização de processos psicológicos que são subjacentes à capacidade do indivíduo de mentalizar, conceito que tem sido descrito tanto na literatura psicanalítica como na cognitiva (Fonagy $\&$ cols., 2002). A função reflexiva envolve tanto um self reflexivo (a autorreflexão) como um componente interpessoal que supre idealmente o indivíduo com uma capacidade bem desenvolvida de distinguir as realidades interna e externa, supostas com base nas vivências "reais" e nos processos mentais e emocionais intrapessoais, a partir das comunicações interpessoais.

A aquisição da capacidade de mentalizar, portanto, é parte de um processo intersubjetivo entre a criança e o cuidador, que se desenvolve no contexto de relacionamentos de apego seguro, facultando à criança a possibilidade de alcançar a regulação e o controle das próprias emoções, desenvolvendo a segurança interna, a autoestima e a autonomia (Fonagy, 1999). Tal aquisição equipa a criança para enfrentar realidades familiares e sociais algumas vezes muito duras. $\mathrm{O}$ estabelecimento sólido da função reflexiva tem um efeito protetor, enquanto, ao contrário, seu status relativamente frágil implica numa vulnerabilidade para traumas ulteriores.

Os conceitos de função reflexiva e o de mentalização revelam-se como particularmente promissores, na medida em que permitem outorgar sentido às próprias ações e às ações dos outros. Fonagy $(1999,2000)$ demonstra que se uma criança é capaz de atribuir a atitude aparentemente rechaçante de uma mãe, que não responde às suas necessidades, à tristeza 
por uma perda, em vez de sentir-se simplesmente impotente frente a essa atitude, esta criança está protegida da confusão e de uma visão negativa de si mesma. A capacidade de entender os estados mentais subjacentes às condutas dos pais ou cuidadores primários pode ser particularmente importante quando a criança está exposta a experiências desfavoráveis, como as crises geradas pelas transições familiares, e no extremo destas, a situações abusivas, violentas etc.

Essa discussão assinala a importância que a dimensão representacional do apego assumiu gradativamente. A crescente sofisticação da teoria do apego na abordagem das representações, afastando-se do pressuposto de que o comportamento apenas reflete interações externas, implicou no arrefecimento das objeções a essa teoria por parte dos teóricos da psicanálise (Target, 2005/2007). Colaborou para isso o surgimento da teoria das relações objetais, "mais concentrada nas representações dos relacionamentos emocionais centrais iniciais do que na psicossexualidade, e da psicologia do ego, com sua ênfase no desenvolvimento de capacidades mentais positivas" (p. 178).

Além disso, deve-se assinalar que existem pontos importantes em comum entre a teoria psicanalítica e os princípios básicos da teoria do apego. Um deles, assinalado por Target (2005/2007), é a ideia do trauma psíquico como algo que dilacera e esmaga o ego, desorganizando seu funcionamento e produzindo efeitos em longo prazo. As ideias de Winnicott (1971/1975, 1978/2000, 1979/1982) de espelhamento e contenção pela mãe como estabelecendo a base para o verdadeiro self (seguro, na acepção de Target), e o seu reconhecimento de que o brincar e a criatividade somente podem se desenvolver no contexto de determinadas condições e ambientes proporcionados pelos pais (especialmente uma "mãe suficientemente boa") também são pontos convergentes com a teoria de Bowlby. Nessa mesma linha, pode-se citar as ideias de Bion (1962/1997, 1963/2004) acerca da regulação do afeto e da organização do pensamento, além da importante função de revêrie materna, que permite a transformação de elementos primitivos e terroríficos da experiência do bebê em representações toleráveis e pensáveis.

Target $(2005 / 2007)$ considera que todas essas ideias "possuem elevada consonância com a teoria do apego, a qual, sem dúvida, as amarra em uma estrutura coerente" (p. 178). Para essa autora, esse corpo teórico liga essas ideias psicanalíticas à Biologia, como Freud pretendia, e mais recentemente aos campos do desenvolvimento e da cognição, que vêm assumindo importância crescente para a Psicologia e para o estudo dos transtornos mentais.

Entretanto, Target (2005/2007) assinala que persiste a percepção de um problema para articular ambas as teorias - do apego e psicanálise. Embora a teoria do apego venha abrangendo com crescente sofisticação as experiências emocionais formativas que estão fora da consciência, levanta-se a objeção de que essas experiências são, sobretudo, não conscientes, implícitas ou procedimentais e não dinamicamente inconscientes e decorrentes de conflitos, especialmente os sexuais, foco da psicanálise clássica. Sem esse foco, para alguns, a psicanálise perderia seu cerne e sua singularidade. Porém, Target argumenta, com propriedade, que o estudo da formação da personalidade e da regulação das emoções por meio de aprendizagem procedimental não exige o abandono do modelo motivacional, baseado nas pulsões, nos conflitos e nas defesas, não existindo essa escolha forçosa e excludente. Há evidências, hoje em dia, de que ambos são aspectos importantes da formação do caráter e sintomatologia.

Fica evidente, portanto, a importância da dimensão representacional do apego no estágio atual dessa teoria, suas implicações para a compreensão do desenvolvimento emocional e suas possibilidades de articulação com aspectos importantes da teoria psicanalítica, especialmente na vertente da teoria das relações objetais e nas contribuições daqueles autores que, como vimos, valorizam o ambiente e as experiências que os seres humanos vivenciam nele.

Além disso, a importância e a centralidade do conceito de modelos funcionais ou modelos representacionais internos deve ser, mais uma vez, sublinhada e é possível que ainda não tenha sido explorada completamente em todas as possibilidades que oferece. A pesquisa e a teorização sobre os modelos representacionais ainda se mostram como um campo aberto e com questões importantes a serem investigadas, tais como a unicidade ou especificidade dos modelos representacionais, a questão da sua estabilidade e/ou mudança, as possibilidades de intervenção sobre os mesmos, entre outras. O que nos conduz a considerar as implicações da teoria do apego para a clínica psicológica e para a Psicologia do Desenvolvimento.

\section{Teoria do Apego: Implicações para a Clínica Psicológica, para a Psicologia do Desenvolvimento e para Futuros Estudos}

A literatura e a pesquisa sobre o apego têm focalizado em grande parte a avaliação e a classificação do apego dos indivíduos pesquisados. Nas últimas décadas, grande parte da pesquisa também tem sido dedicada a estender o estudo do apego ao desenvolvimento posterior, para além da infância, porém o foco ainda se concentra na medição das representações ou do comportamento do apego. Identificase o padrão de apego, em crianças, adolescentes e adultos, em geral em amostras não clínicas. Busca-se correlacionar o apego de crianças e seus pais ou predizer o apego futuro. Os instrumentos utilizados costumam ser a Situação Estranha de Ainsworth, ou a Entrevista de Apego Adulto de Main, ou, ainda, instrumentos que em sua maioria derivam destes.

Por outro lado, Main $(1999,2000)$ assinala que, embora tendo sido importante e necessário descrever, classificar e predizer as condutas de apego, uma nova fase no desenvolvimento deste campo deverá colocar à prova nossa compreensão acerca desses fenômenos, tentando controlá-los e alterá-los. Nessa tarefa, a autora acredita que os clínicos podem contribuir, por exemplo, para aumentar a compreensão acerca do apego inseguro, explorando a possibilidade de intervir para ajudar os indivíduos inseguros a alcançar estados de segurança.

Uma outra nova direção para pesquisas neste tópico, para Main (1999, 2000), está relacionada ao desenvolvimento do campo da neurociência, sendo interessante a realização de pesquisas que combinem a avaliação de diferenças no status do apego com avaliações de fisiologia, imagens do cérebro e genética. Para a autora, esses estudos serão tanto mais profícuos quanto puderem incluir avaliações do status neurológico 
e/ou fisiológico, realizadas antes de uma intervenção clínica exitosa, não se limitando a identificar o cérebro ou seus correlatos fisiológicos de apego seguro frente ao inseguro.

Embora haja certa concordância a respeito de que as crianças e os adultos tenham somente poucas figuras de apego, muitos teóricos e pesquisadores acreditam que os bebês formam "hierarquias de apego", nas quais algumas figuras são primárias, outras são secundárias, e assim por diante (Main, 1999). Para Cassidy (1999), uma figura tenderia a ocupar uma primazia sobre as outras figuras de apego, o que essa autora chamou de "monotropia". No entanto, para Main (1999), questões em torno de quão rapidamente um bebê pode substituir figuras de apego primário, da monotropia e das hierarquias de apego permanecem incertas e vagas. Igualmente com relação à questão da formação de novos apegos na vida adulta, já que o apego é um fenômeno que perpassa todo o ciclo vital.

Bowlby (1969/1990) assinalou a possibilidade de múltiplos apegos na infância, embora esse número potencial não seja ilimitado. Cassidy (1999) questiona o curso do desenvolvimento desses múltiplos apegos ao longo do ciclo vital e as similaridades e diferenças na qualidade entre diferentes apegos. Os estudos que exploraram a questão da concordância do apego relativo a diferentes figuras não são conclusivos. Enquanto alguns indicam independência do apego entre diferentes cuidadores (Belsky \& Rovine, 1987; Main \& Weston, 1981), outros identificaram similaridades (Berlin \& Cassidy, 1999; Fox, Kimmerly \& Schafer, 1991; Goossens \& Van Ijzendoorn, 1990; Steele, Steele \& Fonagy, 1996). Cassidy (1999) e Howes (1999), atentos a essas possibilidades, levantam a questão acerca da organização dos modelos representacionais diante da experiência com figuras de apego que contribuem para modelos conflitantes. E se diferentes modelos de figuras de apego eventualmente se tornam integrados, como isso acontece? Tem havido pouco progresso em responder tais questões.

Bretherton e Munhollan (1999) discutem a possibilidade de um bebê seguramente apegado não se tornar uma criança segura. Uma mudança na qualidade afetiva do modelo representacional poderia ocorrer se um cuidador empático e suportivo se tornasse altamente estressado ou profundamente deprimido em decorrência de eventos como desemprego, doença crônica ou perda de suporte social. Segundo as autoras, se esse cuidador ameaça abandonar a criança ou cometer suicídio, a confiança da criança nessa figura se vê abalada, o que pode conduzir a uma reconstrução do modelo representacional do cuidador e do self. Por outro lado, quando as circunstâncias de vida melhoram, ou um suporte efetivo por parte dos outros se torna disponível, um cuidador pode se tornar capacitado a responder mais sensivelmente às necessidades de apego de sua criança, levando-a a revisar seus modelos representacionais do self como digno e valoroso e do cuidador como cuidadoso e receptivo. Todavia, os aspectos defensivos da organização dos modelos representacionais nas relações de apego inseguro implicam em mais dificuldades para tais reconstruções.

Main e cols. (1985) afirmam, da mesma forma que Bowlby acreditava, que tais modelos "são construções ativas e podem ser re-estruturados” (p. 69). Na infância, é possível que os modelos funcionais internos possam ser alterados somente em resposta a mudanças nas experiências concretas. Mas, uma vez atingido o estágio das operações formais do pensamento, é possível que tais modelos possam ser alterados. Essas operações permitem que o indivíduo pense sobre o pensamento, colocando-se de fora de um dado sistema de relacionamento e analisando seu funcionamento. De acordo com Main e cols. (1985), mais do que modelos propriamente ditos, os modelos funcionais internos são melhor concebidos como processos estruturados que servem para obter ou limitar o acesso à informação. Em 2000, Main utilizou o termo estado mentais para as representações ligadas ao apego, referindo-se aos adultos avaliados por meio da AAI. Postulou que os estados mentais inseguros são indicadores da presença de um processo e não de uma estrutura imutável. Esse processo é muito ativo para essa autora, e isso é atestado pelas distorções no uso da linguagem dos adultos aos quais se solicita que descrevam e avaliem sua história de apego, na AAI.

Processos defensivos podem ser mobilizados, no intuito de proteger os modelos representacionais internos (Bretherton \& Munholland, 1999). Eventos da vida cotidiana podem ser interpretados de maneira distorcida ou até mesmo excluídos defensivamente, na medida em que confrontarem os modelos estabelecidos. Em alguns casos, o termo "defensivo" pode nem ser o mais adequado, na medida em que o que poderá estar em jogo é uma atribuição otimista baseada na esperança acerca de algum comportamento do cuidador. Articulando os processos defensivos com a função reguladora de emoções dos relacionamentos e das representações do apego, Bretherton e Munholland sublinham que é importante buscar uma compreensão mais profunda do seu lado positivo, ao invés de se enfatizar apenas o lado negativo e defensivo. Essas autoras defendem uma abordagem mais orientada para o processo no estudo dos modelos representacionais, em consonância com Main (2000), e em como esses modelos são construídos, desenvolvidos e revisados por meio do envolvimento nos relacionamentos de apego.

Considera-se que tais concepções tenham implicações significativas para a Psicologia Clínica, assim como para a Psicologia do Desenvolvimento. Em grande parte, essas implicações estão alicerçadas na discussão acerca da especificidade dos modelos representacionais, e na sua estabilidade ou mudança. Baldwin, Keelan, Fehr, Enns e Koh-Rangarajoo (1996) e Cook (2000) questionam a fixidez com a qual os modelos representacionais relativos às primeiras figuras de apego moldariam os relacionamentos posteriores. Baseados em pesquisas que realizaram, acreditam que a segurança do apego adulto diz respeito a relacionamentos específicos. Assinalam a influência e importância da cognição para essa variabilidade e flexibilidade em relação aos modelos anteriores da infância. Assim, o estilo de apego elaborado na infância não seria generalizável para todos os demais relacionamentos. Haveria variações que dependem de cada relação em particular, das características do parceiro, das experiências que se sucedem, da reciprocidade presente ou não em cada relação.

Essas assertivas permitem pensar em ações voltadas para a intervenção, no campo da Psicologia Clínica, e para a prevenção de apegos inseguros na infância e na adolescência, e de estados mentais inseguros na vida adulta. Main (2000) 
entende que, por exemplo, ainda que o apego inseguro não possa oferecer uma explicação completa do surgimento de dificuldades clínicas ou de tendências antissociais, a possibilidade de auxiliar os indivíduos a desenvolver um estado mental seguro em relação às suas histórias de apego poderia atuar como um fator protetor e favorecer mudanças positivas.

Uma vez que o apego seguro ou inseguro tem sido associado a determinadas características da interação cuidadorcriança, e a determinadas características contextuais (rede de apoio e suporte para os cuidadores, por exemplo), a detecção precoce de tais dificuldades poderia permitir que fossem mobilizados os recursos necessários para sua modificação. O âmbito da educação infantil seria um espaço possível para isso. A atuação das equipes do Programa de Saúde da Família (PSF), vinculado ao Sistema Único de Saúde (SUS), no Brasil, também poderia contemplar esse olhar sobre os vínculos familiares, identificando eventuais dificuldades e promovendo a sua qualidade e fortalecimento.

As implicações dos achados da teoria do apego para a clínica psicológica não são menos significativas. Bowlby (1979/1997) demonstrou que a tarefa do psicoterapeuta consiste em ajudar o paciente a reexaminar os modelos representacionais das figuras de apego e dele mesmo, analisar como tais modelos dirigem suas percepções e ações, como se desenvolveram durante sua infância e adolescência e, caso o paciente julgue conveniente, auxiliá-lo a modificar tais modelos.

Constata-se que, além de Bowlby (1979/1997) considerar que modelos representacionais inadequados, mas persistentes, poderiam coexistir com outros mais apropriados, ele também reconhecia o caráter dinâmico de tais modelos e potencialmente transformável. Pode-se levar em conta, consequentemente, que conflitos e traumas, em maior ou menor grau, assim como experiências favoráveis ou desfavoráveis em graus diversos no que diz respeito às necessidades de proximidade física e afetiva desde a infância mais precoce, fazem parte da vida mental de todo ser humano. Mudam apenas as respostas do ambiente e das principais figuras de apego e a forma e o "equipamento psíquico" com o qual se lida com eles. Tais experiências podem conduzir a representações mais ou menos seguras. Quando esse enfrentamento se der em condições desfavoráveis ou de vulnerabilidade, dada a história e o contexto do indivíduo, devemos intervir sobre as mesmas, possibilitando uma reescrita dessa história, uma reorganização de tais modelos e uma modificação desse contexto.

Dessa forma, cumpre destacar que o crescente reconhecimento da importância da dimensão representacional do apego abre perspectivas da maior importância para a Psicologia Clínica e para a clínica psicanalítica, atraindo o interesse de importantes representantes desse campo, como já foi visto. Slade (1996) sublinha que a qualidade da regulação dos impulsos e do afeto de uma criança, assim como sua capacidade de manejo da angústia e comportamento de exploração estão relacionadas à capacidade da mãe de simbolizar e integrar memórias e afetos emocionalmente carregados, ligados aos seus relacionamentos mais significativos.

Fonagy (2000) assinala que a psicoterapia, qualquer que seja sua forma, trata da reativação da mentalização, uma vez que ela busca estabelecer uma relação de apego seguro com o paciente, criando um contexto interpessoal onde a compreensão dos estados mentais e o reconhecimento do self se converta em um foco. Sendo assim, quando o desenvolvimento da função reflexiva e do apego seguro experimentou uma falha no desenvolvimento da criança, esse desenvolvimento terá que ser resgatado, ou originado, no seio de uma nova relação de "apego-cuidado", incluindo-se aqui a relação terapêutica.

A experiência clínica e as pesquisas no campo da psicanálise vêm sugerindo que, embora historicamente a psicopatologia psicanalítica tenha sido vista como enraizada na falha em resolver determinados conflitos ligados ao desenvolvimento libidinal, em adição a essas falhas deve-se considerar o modo de regulação do afeto e sua determinação da forma e qualidade do desenvolvimento emocional individual (Eagle, 1997; Fonagy, 2007; Slade, 1996, 1999, 2000). A forma como a criança entra nas fases de Treinamento e Reaproximação de Mahler, bem como o modo de abordar os estágios psicossexuais, deriva da habilidade do cuidador de modular sua experiência emocional no curso do seu primeiro ano (Slade, 1996).

Consequentemente, no âmbito da intervenção psicoterapêutica, torna-se decisiva a capacidade do psicoterapeuta de regular e reconhecer as emoções e os estados mentais, aquilo que para o paciente é desconhecido e irreconhecível até então, trazendo conteúdos intoleráveis para o domínio simbólico (Eagle, 1997; Slade, 1996, 1999, 2000). Esses autores assinalam, portanto, a importância da escuta de temas ligados ao apego na situação clínica e a utilidade clínica do conceito de representações e padrões de apego. As contribuições de Main relativas à linguagem e à narrativa, decorrentes da AAI, também são importantes: a linguagem reflete como o outro foi internalizado, e como respondeu às necessidades e busca de proximidade da criança (Slade, 2000).

Em suma, a pesquisa mais recente sobre o apego, na vertente psicanalítica do campo, sinaliza para uma reformulação crucial dessa teoria, no sentido de considerar que a maior meta do apego seria produzir um sistema representacional para os estados e a organização do self(Fonagy \& cols., 2002). Uma criança pode ter experimentado relacionamentos de apego com pais e/ou cuidadores que evidenciaram capacidade para compreender e atribuir sentidos apropriados para sua vida emocional. Se essa experiência houver falhado, ou apresentar lacunas significativas, poderá ser resgatada no contexto de uma relação terapêutica que proporcione uma base segura, uma escuta sensível e empática, capaz de proporcionar uma identificação e regulação apropriada dos estados emocionais, e uma reorganização dos modelos representacionais internos do self, do outro e do mundo como um lugar mais acolhedor e prazeroso de se viver.

\section{Considerações Finais}

A releitura de conceitos centrais na teoria do apego tal como formulada por Bowlby, assim como o exame do estado atual da teorização acerca de tais conceitos empreendida por estudiosos da psicanálise permite constatar que a aproximação e o diálogo entre esses dois campos são bem vindos e promissores. Primeiro, o reconhecimento da importância das experiências reais do ser humano, além das fantasias e da 
dimensão do seu mundo interno é integrador e oferece subsídios significativos para a compreensão do desenvolvimento e da psicopatologia. Segundo, o exame das interfaces entre os componentes afetivos e cognitivos na constituição dos modelos representacionais, proposto pela teoria do apego, também se revela como integrador e promissor em termos de ações de prevenção e intervenção no campo do desenvolvimento e da saúde mental.

Em terceiro e quarto lugares, o crescente reconhecimento da importância da dimensão representacional e o seu papel regulador das emoções e construtor de significados e da realidade, respectivamente, mostram-se como contribuições decisivas para a compreensão dos processos de constituição psíquica, do desenvolvimento emocional e para a definição do rumo de estudos futuros. Esses aspectos - importância da dimensão representacional e seu papel regulador das emoções - implicam uma nova compreensão do processo terapêutico e do seu potencial, especialmente se considerarmos o tratamento de pacientes com histórias de apego desfavoráveis, e no extremo dessas, daqueles que foram vítimas de violências e/ou traumas os mais diversos. Esse constitui o quinto ponto a ser assinalado nessa síntese final.

Supõe-se que a saliência do foco no comportamento de apego está relacionada aos estudos dirigidos aos bebês e às crianças pequenas na primeira fase da teoria, conforme assinalado por Main (2000). A pesquisa crescente com adultos lançou luz sobre a importância da dimensão representacional do apego, permitindo vislumbrar a sofisticação crescente do equipamento psíquico humano. Conforme ele se desenvolve e se complexifica, a dimensão interna ganha saliência sobre o comportamento observável. Sendo assim, em sexto lugar destaca-se a necessidade de superar a dicotomia entre comportamento e representação, compreendendo ambos como dimensões indissociáveis de um processo único e cada vez mais complexo.

Por último, cumpre salientar que reconhecer e atribuir um determinado padrão de apego a um indivíduo, em que pese a importância que tal atribuição possa ter, talvez implique uma utilidade limitada para esse indivíduo. Além disso, pode-se questionar a existência de padrões de apego únicos, "puros" e imutáveis como foi discutido aqui. Destaca-se a necessidade de superar a ênfase na avaliação e classificação dos padrões de apego, empreendendo um movimento no sentido da intervenção sobre os mesmos, seja em nível de promoção e prevenção, seja no nível das intervenções clínicas.

\section{Referências}

Ainsworth, M. D. (1989). Attachments beyond infancy. American Psychologist, 44, 709-716.

Baldwin, M. W., Keelan, J. P. R., Fehr, B., Enns, V., \& KohRangarajoo, E. (1996). Social- cognitive conceptualization of attachment working models: Availability and accessibility effects. Journal of Personality and Social Psychology, 71, 94-109.

Belsky, J., \& Rovine, M. (1987). Temperament and attachment security within strange situation: An empirical rapprochment. Child Development, 58, 787-795.
Berlin, L. J., \& Cassidy, J. (1999). Relations among relationships: Contributions from attachment theory and research. Em J. Cassidy \& P. R. Shaver (Orgs.), Handbook of attachment: Theory, research and clinical applications (pp. 688-712). New York: Guilford.

Bion, W. R. (1997). Aprendiendo de la experiência (H. Fernández, Trad.). Barcelona: Paidos. (Trabalho original publicado em 1962)

Bion, W. R. (2004). Elementos de psicanálise (J. Salomão, Trad.). Rio de Janeiro: Imago. (Trabalho original publicado em 1963)

Bowlby, J. (1989). Uma base segura: aplicações clínicas da teoria do apego (S. M. Barros, Trad.). Porto Alegre: Artes Médicas. (Trabalho original publicado em 1988)

Bowlby, J. (1990). Apego e perda, Vol 1. Apego: a natureza do vínculo ( $2^{\mathrm{a}}$ ed). São Paulo: Martins Fontes. (Trabalho original publicado em 1969)

Bowlby, J. (1997). Formação e rompimento dos laços afetivos ( $3^{a}$ ed.). São Paulo: Martins Fontes. (Trabalho original publicado em 1979)

Bowlby, J. (1998a). Apego e perda, Vol. 2. Separação: angústia e raiva ( $3^{\mathrm{a}}$ ed). São Paulo: Martins Fontes. (Trabalho original publicado em 1973)

Bowlby, J. (1998b). Apego e Perda, Vol 3. Perda: tristeza e depressão (2 $\left.{ }^{\mathrm{a}} \mathrm{ed}\right)$. São Paulo: Martins Fontes. (Trabalho original publicado em 1973)

Bretherton, I., \& Munholland, K. A. (1999). Internal working models in attachment relationships. Em J. Cassidy \& P. R. Shaver (Orgs.), Handbook of attachment: Theory, research and clinical applications (pp. 89-111). New York: Guilford.

Cassidy, J. (1999). The nature of the child's ties. Em J. Cassidy \& P. R. Shaver (Orgs.), Handbook of attachment: Theory, research and clinical applications (pp. 3-20). New York: Guilford.

Cook, W. L. (2000). Understanding attachment security in family context. Journal of Personality and Social Psychology, 78, 285-294.

Eagle, M. (1997). Attachment and psychoanalysis. British Journal of Medical Psychology, 70, 217-229.

Fonagy, P. (1999). Persistências transgeneracionales del apego: Uma nova teoria. Revista de Psicoanalisis. Aperturas Psicoanalíticas, 3. Retirado em 29/11/2007, de http://www. aperturas.org/23fonagy.html.

Fonagy, P. (2000). Apegos patológicos y acción terapéutica. Revista de Psicoanalisis. Aperturas Psicoanaliticas, 4. Retirado em 29/11/2007, de http://www.aperturas.org/4fonagy.html.

Fonagy, P. (2001). Attachment theory and psychoanalisis. New York: Other.

Fonagy, P. (2007). Teoria psicanalítica do desenvolvimento. Em E. S. Person, A. M. Cooper \& G. O. Gabbard (Orgs.), Compêndio de psicanálise (pp. 143-156). Porto Alegre: Artmed.

Fonagy, P., Gergely, G., Jurist, E. L., \& Target, M. (2002). Affect regulation, mentalization, and the development of the self. New York: Other.

Fox, N. A., Kimmerly, N. L., \& Schafer, W. D. (1991). Attachment to mother/attachment to father: A meta-analysis. Child Development, 62, 210-225.

George, C., Kaplan, N., \& Main, M. (1985). The adult attachment interview. Unpublished manuscript, University of California, Berkeley. 
Goossens, F. A., \& Van Ijzendoorn, M. (1990). Quality of infant's attachments to professional caregivers: Relations to infantparent attachment and daycare characteristics. Child Development, 61, 832-837.

Howes, C. (1999). Attachment relationships in the context of multiple caregivers. Em J. Cassidy \& P. R. Shaver (Orgs.), Handbook of attachment: Theory, research and clinical applications (pp. 671-687). New York: Guilford.

Lyons-Ruth, K., \& Jacobovitz, D. (1999). Attachment disorganization: Unresolved loss, relational violence, and lapses in behavioral and attentional strategies. Em J. Cassidy \& P. R. Shaver (Orgs.), Handbook of attachment: Theory, research and clinical applications (pp. 520-554). New York: Guilford.

Main, M. (1999). Attachment theory: Eighteen points with suggestions for future studies. Em J. Cassidy \& P. R. Shaver (Orgs.), Handbook of attachment: Theory, research and clinical applications (pp. 845-888). New York: Guilford.

Main, M. (2000). The organized categories of infant, child and adult attachment: Flexible vs. inflexible attention under attachmentrelated stress. Journal of the American Psychoanalytic Association. 48, 1055-1127.

Main, M., Kaplan, N., \& Cassidy, J. (1985). Security in infancy, childhood, and adulthhood: A move to the level of representation. Em I. Bretherton \& E. Waters (Org.), Growing points of attachment theory and research. Monografhs of the Society for Research in Child Development, 50, 66-106.

Main, M., \& Weston, D. (1981). The quality of the toddler's relationship to mother and to father: Related to conflict behavior and the readiness to establish new relationships. Child Development, 52, 932-940.

Slade, A. (1996). A view attachment theory and research. Journal of Clinical Psychoanalysis, 5, 112-123.
Slade, A. (1999). Attachment theory and research: Implications for the theory and practice of individual psychotherapy with adults. Em J. Cassidy \& P. R. Shaver (Orgs.), Handbook of attachment: Theory, research and clinical applications (pp. 575-594). New York: Guilford.

Slade, A. (2000). The development and organization of attachment: Implications for psychoanalysis. Journal American Psychoanalytic Association, 48, 1147-1174.

Steele, H. Steele, M., \& Fonagy, P. (1996). Associations among attachment classifications of mothers, fathers and their infants. Child Development, 67, 541-555.

Target, M. (2007). Teoria e pesquisa sobre apego. Em E. S. Person, A. M. Cooper, \& G. O. Gabbard (Org.), Compêndio de psicanálise (pp. 169-182) (D. Bueno, Trad.). Porto Alegre: Artmed. (Trabalho original publicado em 2005)

Winnicott, D. (1975). O brincar e a realidade (J. O. A. Abreu e V. Nobre, Trad.). Rio de Janeiro: Imago. (Trabalho original publicado em 1971)

Winnicott, D. (1982). O ambiente e os processos de maturação (I. C. S. Ortiz, Trad.). Porto Alegre: ArteMed. (Trabalho original publicado em 1979)

Winnicott, D. (2000). Da pediatria à psicanálise (J. Russo, Trad.). Rio de Janeiro: Imago. (Trabalho original publicado em 1978) 